\section{Periodismo de opinión y poder en el Perú}

\author{
María Teresa Quiroz
}

Investigación se propone estudiar la relación entre el periodismo de opinión, la sociedad y la política en el Perú en esta etapa de transición democrática, en medio de una sociedad pobre, con un alto grado de desigualdad social y una baja consistencia ciudadana. Se tratará de detectar las formas a través de las cuales los principales diarios ejercen la opinión, su incidencia en la agenda pública y en la vida política. Asimismo, se examinarán las líneas editoriales y sus acomodos o reacomodos en relación con la situación política del país.

Algunas de las preguntas que se trata de responder son las siguientes: ¿Existen líneas editoriales sólidas en los diarios El Comercio, Perú 21, La República, Correo, Expreso y La Razón? ¿Qué cambios se han producido en las líneas editoriales de estos diarios en los últimos años? ¿Se puede hablar de "representación" de posiciones o de tendencias que representan intereses de grupo o de partidos políticos? ¿De qué modo las opiniones de los diarios o de los periodistas inciden de manera directa en la vida política nacional? ¿A qué sectores de la ciudadanía alcanza el periodismo de opinión? ¿Tiene el periodismo de opinión incidencia sobre una sociedad atrasada, descom-

1 Resumen de un trabajo que se realiza en el Instituto de Investigación de la Universidad de Lima. 
puesta y con rezagos autoritarios como la peruana? ¿Quiénes son los periodistas que ejercen la opinión en estos diarios y cuál es su punto de vista sobre su quehacer y responsabilidad periodística? ¿Qué nivel de profesionalización alcanza el periodismo de opinión?

Voy a detenerme en dos aspectos que son de interés para los propósitos de la investigación: los dilemas de la democracia peruana y algunas reflexiones sobre el periodismo de opinión.

\section{Los dilemas de la democracia peruana}

Podría decir que los actuales problemas de la democracia en el Perú son los siguientes:

- La estabilidad de las formas democráticas. Afirmamos siempre que hemos salido de un gobierno autoritario pero no de una historia, de una cultura y de unas instituciones autoritarias. Nadie puede sentirse seguro respecto al futuro democrático del Perú en los próximos años. Menos aún si se observan los muy recientes malestares en diversos frentes (demandas regionales, crisis creciente de los partidos, dificultades en la gobernabilidad, malestar en las fuerzas armadas, etcétera).

- La gobernabilidad democrática. Agotado el consenso de Washington, la tensión entre las exigencias del crecimiento económico y las demandas sociales no encuentra aún un derrotero seguro de solución. Después del fracaso de las privatizaciones en Arequipa en el 2002, los dirigentes políticos peruanos no han podido concretar una política de mejora de la competitividad y estímulo a la inversión privada que sea compatible con la necesidad de aliviar la pobreza. No hay propuestas de fondo (a pesar del Acuerdo Nacional), ni mucho menos consensos, sobre el proceso político y económico de la descentralización, librada a la confrontación superficial entre intereses menudos y coyunturales. La agenda política es gaseosa y pobre.

- La calidad de la democracia. En todo el mundo, la extensión generalizada de las formas democráticas viene acompañada de una decreciente intensidad en la vida democrática. Esta es la paradoja de la democracia contemporánea: nunca tan extensa, nunca menos intensa. Los mercados en que los políticos ofrecen propuestas para convencer a electores-ciudadanos van siendo sustituidos por escenarios mediáticos donde los políticos solo ofrecen mensajes publicitarios para seducir a electores-consumidores.

La pérdida de la calidad provoca falta de adhesión y desconfianza en la democracia, lo cual hace a esta 
aún más frágil y precaria. Esto se hace evidente en la encuesta de setiembre del 2003 "Opinión ciudadana sobre partidos políticos”, realizada por el Grupo de Opinión Pública de la Universidad de Lima, Transparencia e Idea Internacional. Los resultados indican que si bien el 81 por ciento prefiere un gobierno democrático a una dictadura, el 88 por ciento está poco o nada satisfecho con ella. Asimismo, más del 80 por ciento no confía ni en los partidos políticos ni en el gobierno y el 55 por ciento tampoco confía en los medios de comunicación.

\section{Algunas reflexiones sobre el periodismo de opinión}

Vivimos un tiempo de "laberinto" de la información, abundante y contaminada. La opinión está presente no solo en los artículos firmados y de opinión específicamente, sino también en los titulares, en las "notas breves", en las caricaturas, etcétera. Hay que desarrollar, como en los alimentos orgánicos, una ecología de la información: "descontaminar y consumir la información que consideremos más pura y basada en la confianza. Esto pasa por una relación más fuerte con las firmas y las personalidades en los medios". ${ }^{2}$
Es por ello que muchos estudiosos piensan que los diarios están llamados a cumplir un nuevo papel en el complicado escenario mundial, agregándole a la información calidad de escritura y reflexión sólida. Eso requiere contar con periodistas que "desconfíen" de la información que le llega naturalmente o por la internet y busquen comparar e investigar. Lo que se espera del periodismo de opinión es el análisis, la confrontación de fuentes que permitan acceder a conclusiones originales.

¿Qué es la verdad hoy en día? ¿Dónde está la verdad para el público? Basta que haya simultaneidad en la información en la prensa, la radio y la televisión para que el público crea que es la verdad, aunque no lo sea. En general, podría afirmarse que el ciudadano no siempre tiene los elementos para distinguir. Si un buen diario es aquel que sirve de punto fijo a los ciudadanos, que proporciona fuentes confiables, podemos concluir que la calidad principal de un medio está en su credibilidad. Esto ocurre cuando el lector puede tener, regularmente, la prueba de que entre lo que afirma el medio y la realidad no hay diferencias. El público necesita reafirmar el pacto de credibilidad con el medio. Sin embargo, algunos medios anonimizan a sus periodistas, aunque es interesante poner

2 RAMONET, Ignacio. Entrevista divulgada por el diario El Comercio. Lima, julio del 2003. 
de relieve que en el mundo de hoy hay una tendencia que está redescubriendo el interés por los columnistas.

Hay un hecho que puede destacarse: el 11 de setiembre derrumbó la admiración por el periodismo americano de calidad, produciendo un conflicto entre el periodismo que reacciona con patriotismo y el profesionalismo. Ello, sin contar los cientos de casos de censura. La idea de la guerra del bien contra el mal se ha extendido a la prensa.

La información actual se caracteriza por su abundancia (a pesar de que durante siglos fue escasa); por su ritmo rápido y porque su valor está cada vez más referido a cómo se ubica como mercancía como parte de las leyes del mercado. Informar es esencialmente hacer asistir a un acontecimiento, mostrarlo, situarse a un nivel en el que el objetivo es decir que la mejor manera de informarse equivale a hacerlo directamente. La idea de la autoinformación se va imponiendo como parte de un sistema que incorpora la idea de que "ver es comprender". Por ese motivo, la actualidad es básicamente lo que dice el medio de comunicación dominante. Si este afirma que algo forma parte de la actualidad, los demás medios de comunicación lo repetirán. Es evidente que la televisión impondrá como actualidad todos aquellos acontecimientos que sean propios de su ámbito, acontecimientos esencialmente ricos en capital visual y en imáge- nes. Cualquier suceso de índole abstracto no estará nunca de actualidad en un medio de comunicación que es, ante todo, visual.

Ha cambiado otro aspecto y es el de la especificidad de cada medio de comunicación. Durante mucho tiempo se podían contraponer entre sí prensa escrita, radio y televisión. Es cada vez más difícil hacer que compitan entre sí, porque los medios de comunicación hablan de sí mismos, repiten lo que dicen los otros medios de comunicación, lo dicen todo y, a la vez, dicen lo contrario. Así, pues, constituyen, cada vez más, una esfera de la información y un sistema único en el que es difícil hacer distinciones. Se podría decir también que este conjunto se complica a causa de la revolución tecnológica.

Hasta ahora, en el mundo de la comunicación disponíamos de tres sistemas de signos: el texto escrito, el sonido de la radio y la imagen. Cada uno de ellos ha dado lugar a un sistema tecnológico. La revolución numérica está haciendo converger de nuevo los sistemas de signos hacia un sistema único: texto, sonido e imagen pueden expresarse en forma de bites, son los llamados multimedia. El sistema de comunicaciones crea una red, un tejido que envuelve al conjunto del planeta, permitiendo el intercambio intensivo de información.

Dadas las condiciones industriales de la producción informativa, un pe- 
riodista tiene cada vez mayor tendencia a convertirse en un simple vehículo, como canal que enlaza el suceso y su difusión. No tiene tiempo de filtrar ni de comparar, porque si pierde mucho tiempo haciéndolo, sus colegas le ganarían la partida.

Estamos en un sistema que poco a poco considera que hay valores importantes (instantaneidad, masificación) y valores menos importantes, es decir menos rentables (los criterios de verdad). La información se ha convertido ante todo en una mercancía, ya no tiene una función cívica.

Por muy abundante que sea la información, lo que más interesa es que sea creíble y fiable y, por tanto, que contenga un mínimo de garantías relacionadas con la ética, la honestidad, la deontología o la moral de la información. La cuestión de la ética se sitúa ahora en el centro de la preocupación de los periodistas. En nombre de la industrialización de la información, el ámbito de actividad de estos se ha reducido considerablemente y es evidente que se enfrentan, en la mayoría de casos, a un sistema tanto de jerarquía como de propiedad, que reclama una rentabilidad inmediata. Muchos periodistas acabarán limitándose a ser el canal que transfiere la comunicación emitida por tal o cual industria, tal o cual institución política, económica, cultural o social.
Los medios ya no pueden presentarse simplemente como un ojo que mira, pero que no se ve a sí mismo. La gente espera que los medios se autocritiquen y que procedan a analizar con mayor seriedad su propio funcionamiento. No han de tener una posición privilegiada. No existen solo para juzgar a los demás sino también para ser juzgados. Cuando cometen errores, deben ser los primeros en reconocerlos.

En los últimos tiempos se han dado muestras de preocupación e interés por tratar el tema. Hace un par de años se produjo un debate importante entre periodistas acerca de la función periodística y sus limitaciones, promovido por el Instituto Prensa y Sociedad (IPYS). Se partió de la pregunta: ¿El periodismo se está pasando de la raya? Participaron Mirko Lauer, Enrique Zileri, Cecilia Valenzuela, Ricardo Uceda, Santiago Pedraglio y Gustavo Gorriti. Luego de esto se ha abierto una página en internet, a través de la cual se debaten asuntos como los siguientes: a) el control de calidad sobre los productos periodísticos, b) sobre si el trabajo periodístico varía de acuerdo a las condiciones políticas y a los regímenes autoritarios o democráticos, y c) sobre las fuentes de información y la calidad de las fuentes, así como acerca de la información de interés público.

Hasta aquí algunos avances de la investigación. 